\title{
An Affordable Custom-Built Negative Pressure Wound Therapy
}

\author{
Alshazaly Mohamed Abdal-Kareem Isaac, Mohamed Elamin Salim, Ihab Abdel-Rahim Mohamed Ahmed \\ Department of Surgery, Sharg El-Neel Hospital - Khartoum, Sudan
}

Correspondence to: Dr. Ahmed Ihab Abdel-Rahim Mohamed, P.O. Box 789 Khartoum, Sudan.

Email: ihabahmed@doctors.org.uk

\begin{abstract}
Negative pressure wound therapy (NPWT) is a wellestablished and effective method for treating complex wounds. However, this modality of treatment may not be available in limited resource countries due to the high cost. We describe a simple and cheap method of NPWT using gauze swabs, a naso-gastric tube, adhesive occlusive drape and a central or portable
\end{abstract}

Negative pressure wound therapy (NPWT) is a wellestablished modality for treating complex wounds (1). There are several proposed mechanisms of action of NPWT (2). The main disadvantage of NPWT is that it is expensive, a drawback that makes this modality of treatment not available in limited-resources countries. A simplified NPWT device has been previously described (3). Here, we describe another simple and inexpensive method of NPWT.

After meticulous cleaning, a sterile laparotomy gauze swab, $30 \mathrm{~cm} \times 30 \mathrm{~cm}$ or $40 \mathrm{~cm} \times 40 \mathrm{~cm}$, that is lightly soaked in normal saline is laid directly onto the surface of the wound. A 16 Fr naso-gastric (NG) tube is placed on the gauze and another piece of sterile gauze is placed over the NG tube. This is then covered with a transparent adhesive occlusive drape. The NG tube is then connected to a central or portable suction system (Figure 1-3). When the suction is turned on, it induces a negative pressure which causes a characteristic shrinking of the gauze, indicating that the device is functioning and that there was no leak of air. The dressing is changed every 48 to 72 hours, depending of the state of the wound and surgeon's preference.

We have applied this simplified technique of NPWT in patients with diabetic foot ulcers and open fractures. Good outcome, in terms of wound healing and inducing healthy granulation tissues suitable for skin graft, was suction machine.

Key words: Negative Pressure, Wound Therapy Ann Afr Surg. 2017;14(1): 55-56.

DOI: http://dx.doi.org/10.4314/aas.v14i1.12

(C) 2017 Annals of African Surgery. This work is licensed under the Creative Commons Attribution 4.0 International License.

achieved in most cases.

In conclusion, this is an effective, cheap and affordable alternative to the original NPWT which would be suitable in limited-resources countries.

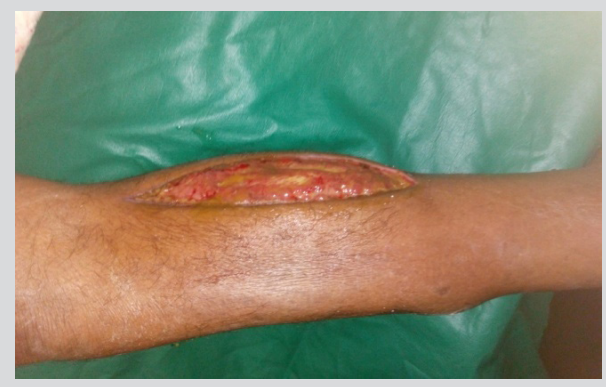

Figure 1. Clean wound after thorough cleaning.

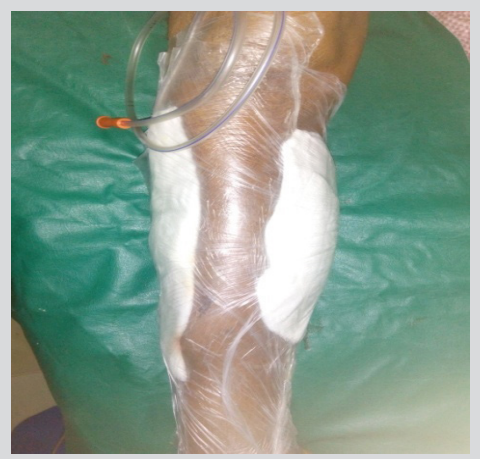

Figure 2: Wound after applying the abdominal gauze swab, placing the NG tube and applying the adhesive dressing. 


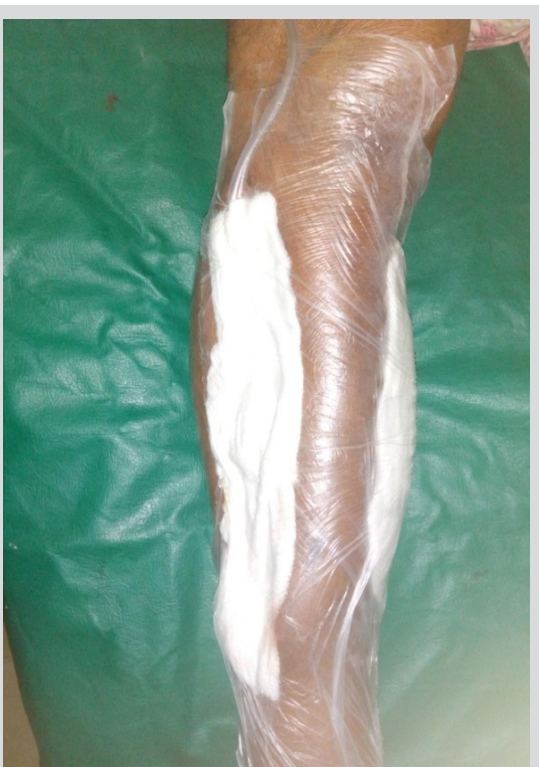

\section{References}

1. Argenta LC, Morykwas MJ. Vacuum-assisted Closure: A New Method for Wound Control and Treatment: Clinical Experience. Ann Plast Surg. 1997; 38: 563-76.

2. Schintler MV. Negative Pressure Therapy: Theory and Practice. Diabetes Metab Res Rev. 2012; 28: S72-7.

3. Zurovcik DR, Mody GN, Riviello R, et al. Simplified Negative Pressure Wound Therapy Device for Application in Low-Resource Settings. J Orthop Trauma. 2015; 29 Suppl 10:S33-6.

Figure 3: After turning the suction on 